\section{Study of implementation and direct cost estimates for diagnostic tests for human visceral leishmaniasis in an urban area in Brazil}

\author{
Estudo da implantação e estimativas de custo \\ direto de testes diagnósticos para leishmaniose \\ visceral humana em uma área urbana no Brasil
}

\author{
Estudio de la implementación y el costo directo \\ estimado de pruebas de diagnóstico de la \\ leishmaniasis visceral humana en una \\ zona urbana en Brasil
}

Tália Santana Machado de Assis 1,2 Paloma Nogueira Guimarães 1 Edward Oliveira ${ }^{1}$ Vanessa Peruhype-Magalhães 1 Luciana Inácia Gomes 1 Ana Rabello ${ }^{1}$

\footnotetext{
1 Centro de Pesquisas René Rachou, Fundação Oswaldo Cruz, Belo Horizonte, Brasil. 2 Centro Federal de Educação Tecnológica de Minas Gerais, Contagem, Brasil.

Correspondence T. S. Machado de Assis Centro de Pesquisas René Rachou, Fundação Oswaldo Cruz. Av. Augusto de Lima 1715 Belo Horizonte, $M G$ 30190-002, Brasil. taliadeassis@yahoo.com.br
}

\begin{abstract}
This work reports the process and costs of comprehensively implementing two tests to decentralize the diagnosis of visceral leishmaniasis (VL) in an endemic city in Brazil: a rapid test (IT LEISH) and a direct agglutination test (DAT LPC). The implementation began by training health professionals to perform the tests. Estimation of the training costs considered the proportional remuneration of all professionals involved and the direct costs of the tests used for training. The study was conducted between November 2011 and November 2013. During that time, 17 training sessions were held, and 175 professionals were trained. The training cost for each professional was US\$ 7.13 for the IT LEISH and US\$ 9.93 for the DAT-LPC. The direct costs of the IT LEISH and DAT-LPC were estimated to be US\$ 6.62 and US\$ 5.44, respectively. This first evaluation of the implementation of these diagnostic tests indicates the feasibility of decentralizing both methods to extend access to VL diagnosis in Brazil.
\end{abstract}

Leishmaniasis; Diagnosis; Costs and Cost Analysis

\section{Resumo}

Este trabalho relata o processo e os custos da implantação de dois testes para descentralizar o diagnóstico da leishmaniose visceral (LV) em um município endêmico no Brasil: um teste rápido (IT LEISH) e um teste de aglutinação direta (DAT-LPC). A implantação iniciou com o treinamento dos profissionais de saúde do município na realização dos testes diagnósticos. Os itens incluídos nas estimativas de custo das capacitações foram a remuneração proporcional de todos os profissionais envolvidos e os custos diretos dos testes usados. O estudo foi conduzido entre novembro de 2011 e novembro de 2013. Durante esse período, 17 capacitações foram realizadas e 175 profissionais treinados. O custo relacionado a cada profissional de saúde capacitado na realização do IT LEISH foi de US\$ 7,13 e na realização do DAT-LPC, de US\$ 9,93. O custo direto do IT LEISH e do DAT-LPC foi estimado em US\$ 6,62 e US\$ 5,44, respectivamente. Esta primeira avaliação da implantação desses dois testes aponta para a viabilidade da descentralização de ambos os métodos, que aumentam o acesso ao diagnóstico da LV no Brasil.

Leishmaniose; Diagnóstico; Custos e Análise de Custo 


\section{Introduction}

Visceral leishmaniasis (VL) is a serious parasitic disease that affects patients' productivity and quality of life $1,2,3$. It is estimated that the disease is responsible for 200,000-400,000 new cases worldwide every year 4. In Brazil, 22,642 cases of VL were recorded between 2007 and 2012, with 1,368 deaths (Brazilian Information System for Notifiable Diseases - SINAN. http://dtr2004.saude.gov.br/sinanweb/tabnet/ tabnet?sinannet/leishvi/bases/leishvbrnet.def, accessed on 14/Jul/2014). Currently, the country is facing a change in the epidemiological profile of VL: this disease, which has been characterized as endemic in rural areas, has been expanding and urbanizing, appearing in large cities, such as Belo Horizonte, Minas Gerais State and Teresina, Piauí State. The increase in the number of cases of the disease may be related to migration and urbanization. These processes most often occur in a disorderly manner, resulting in poor living conditions and environmental destruction, which are factors that may influence the emergence of VL 5,6. In this context, the main goal of the Ministry of Health is to reduce the numbers of cases and deaths through early diagnosis and treatment 7 .

According to Brazilian Ministry of Health recommendations, clinically suspected cases of VL can be confirmed through epidemiological or laboratory criteria. Based on the latter, the patient must test positive using at least one of the following assays: direct parasitological or bone marrow aspirate culture, an indirect fluorescence antibody test (IFAT) or a rapid test for anti-rK39 antibody detection 7. Currently, the Brazilian Minsitry of Health offers the Kala-Azar Detect rapid test (Inbios International, USA), which has been standardized for use in serum, and an IFAT produced by Biomanguinhos/Oswaldo Cruz Foundation (Fiocruz), Brazil, in its system of reference laboratories.

Parasitological examination, which requires bone marrow aspirate, is considered the gold standard for diagnosing VL; however, it is an invasive procedure and requires an infrastructure of medium complexity as well as medical specialists and trained laboratory technicians. In addition to the operational difficulties, the detection of parasites in bone marrow aspirate has poor performance, with a sensitivity varying from $64 \%-77 \% 8,9,10$.

The IFAT is Brazil's most widely used serological test for VL diagnosis. Of the total number of reported VL cases between 2007 and 2012, 86\% $(19,495)$ were confirmed by laboratory criteria; of these, $53 \%(10,346)$ were confirmed by the IFAT 5 .
The sole advantage of the IFAT, considering its poor performance (its sensitivity ranges from $88 \%-92 \%$, and its specificity ranges from $83 \%$ $88 \%$ ), is that it is a domestic product 10,11 . Moreover, similar to the disadvantages of parasitological diagnosis, the IFAT requires a complex infrastructure and trained technicians, thus limiting access and delaying diagnosis and treatment.

The so-called "rapid tests" offer several advantages compared with the two techniques mentioned above because they are easily performed and interpreted and because the result is available in a matter of minutes. In Brazil, the Kala-Azar Detect has been available in reference public laboratories and hospitals since 2009. The test is performed with serum, requiring blood centrifugation and serum preparation, and thus presents a drawback for the point-of-care objective. Test evaluation in Brazil showed low to moderate sensitivity, ranging from $84 \%-90 \%$, and a specificity ranging from $90.6 \%-100 \% 12,13,14$.

Two diagnostic immunological tests that could feasibly replace the IFAT and the Kala-Azar Detect test, which the Brazilian Ministry of Health currently makes available for VL diagnosis, are the direct agglutination test (DAT-LPC) and the IT LEISH rapid test (Bio-Rad Laboratories, USA), respectively. Both tests have been validated in Brazil and have shown high performance, with sensitivity and specificity respectively estimated at $99 \%$ and $98 \%$ for the DAT-LPC 15 and at $92 \%$ 93\% and $92 \%-98 \%$ for the IT LEISH 10,13 .

The DAT-LPC is easily performed and interpreted; it requires a simple infrastructure (centrifuge and pipette) and may be independently produced in Brazil. Conversely, the IT LEISH rapid test exhibits the best performance in the country and can be performed using both serum and digital capillary blood, the latter of which is the advantage that enables its use as a point-ofcare testing method 10,13. The Kala-Azar Detect and IT LEISH are unique rapid tests registered at the Brazilian national regulatory agency (Brazilian National Agency for Sanitary Surveillance ANVISA. http://portal.anvisa.gov.br/wps/portal/ anvisa/home, accessed on 22/Sep/2014) for VL diagnosis and need to be imported.

Replacing the IFAT with the DAT-LPC and replacing the Kala-Azar Detect rapid test with the only point-of-care test currently registered at ANVISA, the IT LEISH, or with another validated and efficient rapid test meant for bedside use, when available, could signify a great advancement in VL diagnostics. These advances are operational, technical, and related to performance and access. The aim of the present study was to describe the implementation process of the IT LEISH rapid test and the DAT-LPC test for diagnosing 
VL in a large-sized city $(100,000-900,000$ inhabitants) in Minas Gerais State, and to estimate the direct costs of their implementation in the city compared with those of the tests presently made available by the Brazilian Ministry of Health.

\section{Materials and methods}

\section{Study site and established partnerships}

The study was performed in Ribeirão das Neves, a city situated $33 \mathrm{~km}$ from Belo Horizonte, the capital of Minas Gerais State. According to 2010 data from the Brazilian Institute of Geography and Statistics (IBGE. http://seriesestatisticas. ibge.gov.br/, accessed on 22/Sep/2014), the city has 296,317 inhabitants and a total area of $155.541 \mathrm{~km}^{2}$. Ribeirão das Neves has 61 health units, 53 of which are part of the Family Health Program (PSF); these include one outpatient clinic for infectious and parasitic diseases, two emergency units, five basic referral units and one hospital. The city has been reporting cases of VL since the year 2000. Between 2008 and 2013, 132 patients who live in the city were diagnosed with the disease, and nine $(6.8 \%)$ of these patients died.

To perform this study, a formal collaboration was established between the Clinical Research Laboratory at the René Rachou Research Center of the Oswaldo Cruz Foundation (CPqRR/ Fiocruz) and the Municipal Health Secretariat (SMS) in Ribeirão das Neves. The Leishmaniasis Reference Center at the CPqRR offered to train health care professionals in the city to perform the diagnostic tests and also provided the IT LEISH to all health services in the municipality, provided the DAT-LPC to the Municipal Laboratory and allocated an investigator to the SMS to support and monitor the activities related to the study. As a counterpart of the CPqRR, the SMS allocated human resources to the city's health units and provided the Municipal Laboratory structure.

\section{Diagnostic testing implementation process}

The process of implementing the diagnostic tests in Ribeirão das Neves began in 2011, with the training of health professionals in how to perform the IT LEISH and the DAT-LPC. Each training session consisted of a theoretical introduction, during which the study background and the informed consent form were presented, followed by technical training, during which the professional performed the diagnostic test.

During IT LEISH training, each professional received a kit containing a rapid test, a protective mask, gloves and an instruction manual. After demonstration of the test, the professionals were encouraged to perform at least one IT LEISH reaction. During DAT-LPC training for professionals at the Municipal Laboratory, the test execution was first demonstrated, and the professionals subsequently performed at least one reaction under supervision. Following completion of the first training courses, rapid test kits were made available to the city's health services, and the DAT-LPC was made available to the Municipal Laboratory. Further training courses were performed as required, primarily due to professional turnover throughout the study period.

To manage the established flowchart and existing routine for VL diagnosis in the municipality according to Ministry of Health recommendations, patients were referred to the Municipal Laboratory for blood collection and performance of the Kala-Azar Detect after completing the IT LEISH at the health units. Patients were referred regardless of the IT LEISH test result. Additionally, serum collected at the Municipal Laboratory was split, and a portion was sent to the regional reference laboratory at Ezequiel Dias Foundation (FUNED), in the Belo Horizonte, for performance of the IFAT. Finally, as part of the study, a subset of the samples was also forwarded to the CPqRR to be retested using the DAT-LPC (quality control) and using polymerase chain reaction (PCR), which is the standard reference test.

\section{Costs}

\section{Training costs}

Estimation of the training costs considered the following factors: (1) the proportional remuneration for a pharmacist/biochemist (monthly salary of US\$ 726.11 and 40-hour workweek in 2012) in Ribeirão das Neves, based on the time spent on providing IT LEISH and DAT-LPC training; and (2) the number of diagnostic tests used during training.

Cost of training each health care professional in performing diagnostic tests

The cost of training one health care professional to perform the IT LEISH and DAT-LPC was estimated by dividing the overall cost of the training courses by the number of professionals trained to perform each diagnostic test. 
Direct costs and estimation of the time needed to perform diagnostic tests

Direct costs include the value of goods, services and other resources that are consumed in the provision of a health intervention (in this case, diagnostic test implementation). In these estimates, only operational costs were considered, assuming that there was no need for specific investments in infrastructure and equipment to supplement the existing minimal infrastructure of the local health care services and the local laboratory. The direct cost of the diagnostic tests included several items, such as safety material, collection of biological material, consumable material, equipment maintenance and calibration and proportional remuneration for the professional who performed the diagnostic test during health service delivery. The IT LEISH kit provides all of the material necessary for the collection of biological material, and when performed with digital capillary blood, as in the present study, this test does not require consumable material or equipment maintenance and calibration. The monthly salary for a laboratory technician was US\$274.32, for a medical specialist (clinical pathologist or hematologist) was US\$ 3,642.68, and for a nurse was US\$ 1,055.64 for a 40-hour work week in 2012 (Guimarães PN, personal comunication).

The CPqRR commercial contracts sector and the companies producing the diagnostic tests constituted the information sources for cost estimates. The estimated costs of equipment maintenance and calibration were based on 100 suspected cases of human VL (15 confirmed cases of VL and 85 cases of other diseases) reported in Ribeirão das Neves in 2012 and on the working capacity of the equipment. All values were originally estimated in Brazilian currency, or the Real (BRL), and subsequently converted into US dollars (US\$ $=2.21$ on April 11, 2014).

The estimates of testing time totaled all of the time spent performing the diagnostic tests, from the collection of biological material until the release of the result, assuming that the test was the exclusive activity conducted by the professional during the testing period.

\section{Ethical aspects}

The Ethical Research Committee of the CPqRR had previously approved the informed consent forms and procedures (n. 21/2011). The clinical study was conducted in accordance with the $\mathrm{Hel}$ sinki Declaration, Good Clinical Practice (ICH 1996) and the Brazilian National Health Council (CNS) Resolutions n. 196/1996 and 251/1997.

\section{Results}

The implementation study for the IT LEISH rapid test and the DAT-LPC in health service units in Ribeirão das Neves was performed between November 2011 and November 2013. During this period, there were 17 training courses for health professionals, 15 of which were related to the IT LEISH and two of which were related to the DATLPC. The latter were implemented at the Municipal Laboratory, and the IT LEISH was implemented at all 62 of the city's health units. In total, 175 professionals (15 medical doctors, 72 nurses, 73 nurse technicians, 12 laboratory technicians, a pharmacist, a biochemist and a psychologist) were trained (Table 1), 162 of whom were trained to perform the IT LEISH and 13 of whom were trained to perform the DAT-LPC. Of the 175 professionals who were trained, 124 (71\%) continued to implement the tests until the end of the study.

Five researchers were involved in the training, one of whom was available at the MHS throughout every working day each week. Each course related to the IT LEISH lasted 100 minutes on average (range - maximum and minimum: 40-240 minutes), and each course related to the DAT-LPC lasted 150 minutes on average (range maximum and minimum: 120-180 minutes) (Table 1). Given that the researchers' wages varied considerably, we chose to estimate the cost of the training professionals based on the salary of a pharmacist/biochemist in Ribeirão das Neves.

The remuneration costs for five biochemists over the course of the training period for the IT LEISH (15 courses) and the DAT-LPC (2 courses) were estimated to be US\$ 156.06 and US\$ 42.12, respectively. In the 17 training courses, a total of 151 rapid tests and 16 DAT-LPC tests were used; the expenses related to use of the kits and performance of the reactions were estimated to be US\$ 999.62 and US\$ 87.04, respectively (Table 2). Therefore, the cost to train each health professional was estimated at US\$ 7.13 for the implementation of the IT LEISH (US\$ 1,155.68 of proportional remuneration for five biochemists to provide IT LEISH training plus the total value of the rapid tests used during the trainings divided by the 162 health professionals trained) and US\$ 9.93 for the implementation of the DAT-LPC (US\$ 129.16 of proportional remuneration for five biochemists to provide DAT-LPC training plus the total value of the reactions performed divided by the 13 health professionals trained).

Throughout the study period, four lots of IT LEISH and three lots of DAT-LPC were made available before their expiration date. The expiration date of the first three batches of IT LEISH was six months, and that of the last was one year. 
Estimates related to the implementation of the IT LEISH rapid test and the DAT-LPC in Ribeirão das Neves, Minas Gerais State, Brazil, between November 2011 and 2013.

Estimate (range - maximum and minimum)

\begin{tabular}{lc}
\hline Number of training courses held related to the IT LEISH & 15 \\
Number of training courses held related to the DAT-LPC & 2 \\
Number of professionals trained in total & 175 \\
Number of researchers involved in the training courses & 5 \\
Average length of training courses related to the IT LEISH & 100 minutes (40-240) \\
Average length of training courses related to the DAT-LPC & 150 minutes (120-180)
\end{tabular}

DAT-LPC: direct agglutination test.

Table 2

Costs of 17 training courses for implementing the IT LEISH rapid test and the DAT-LPC in all health service units and a local laboratory in Ribeirão das Neves, Minas Gerais State, Brazil, from 2011 to 2013.

Items included in the cost analysis

Estimate (US\$)

Proportional remuneration for five biochemists to provide training in performing the IT LEISH

156.06

IT LEISH rapid tests used (151)

999.62

Proportional remuneration for five biochemists to provide training in performing the DAT-LPC

42.12

DAT-LPC reactions used (16)

87.04

Total cost of training courses for the DAT-LPC and IT LEISH

DAT-LPC: direct agglutination test.

The DAT-LPC was always provided with an expiration date of two years. The direct cost and performance time of the tests in Ribeirão das Neves were respectively estimated to be US\$ 6.62 and 30 minutes for the IT LEISH and US\$ 5.44 and 50 minutes for the DAT-LPC. All of the other tests evaluated had higher direct costs and performance times (Kala-Azar Detect rapid test US\$ 6.72 and 60 minutes; bone marrow aspirateUS $\$ 26.85$ and 130 minutes; IFAT - US $\$ 12.54$ and 140 minutes; PCR - US\$ 34.02 and 200 minutes) (Table 3). Table 4 presents the detailed costs of the items included in direct cost estimates of the diagnostic tests.

\section{Discussion}

The incorporation of new technologies in health services requires a strict and organized followup because access to diagnosis is not sufficient to ensure improvement in health care quality. Linked to follow-up is the establishment of an organized technical assistance network that de- fines and delineates responsibilities among the various levels of health care 16,17 . In the present study, implementation of the IT LEISH rapid test and the DAT-LPC test occurred gradually, with training of health professionals in the proposed methodologies and preparation of health service delivery units to implement the tests efficiently.

The serological tests available for diagnosing VL in Brazil do not fulfill all of the necessary requirements for efficient coverage of the affected population. Replacing the IFAT with the DAT-LPC and replacing the Kala-Azar Detect with a kit that uses capillary blood and that therefore allows on-site diagnosis (such as the IT LEISH used in this area) could increase access to diagnosis of the disease in Brazil. Among the advantages offered by the DAT-LPC is the possibility that the kit could be produced in Brazil 15, and among the advantages of the IT LEISH is the possibility of performing the test at patients' bedside 10,11,12,13. However, rapid test production needs to be encouraged on a national scale.

The DAT-LPC is not a commercially available test. Currently, two European laboratories com- 
Table 3

Direct cost, location and time for performing the evaluated diagnostic tests.

\begin{tabular}{|c|c|c|c|c|}
\hline Diagnostic test & $\begin{array}{l}\text { Direct cost of } \\
\text { one test (US\$) }\end{array}$ & $\begin{array}{l}\text { Performance } \\
\text { location }\end{array}$ & $\begin{array}{l}\text { Time for collection and } \\
\text { processing of biological } \\
\text { material in minutes }\end{array}$ & $\begin{array}{c}\text { Total time required to } \\
\text { perform tests in minutes } 3 \text { * }\end{array}$ \\
\hline IT LEISH rapid test & 6.62 & Ribeirão das Neves & 2 & 30 \\
\hline DAT-LPC & 5.44 & Ribeirão das Neves & 30 & 50 \\
\hline Kala-Azar Detect rapid test & 6.72 & Ribeirão das Neves & 30 & 60 \\
\hline Bone marrow aspirate & 26.85 & $\mathrm{CPqRR}$ ** & 40 & 130 \\
\hline IFAT & 12.54 & 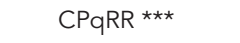 & 30 & 140 \\
\hline PCR & 34.02 & CPqRR *** & 30 & 200 \\
\hline
\end{tabular}

DAT-LPC: direct agglutination test; IFAT: in direct fluorescence antibody test; PCR: polymerase chain reaction.

* The time total ranges from biological material collection and processing to diagnostic test completion;

** Ambulatory of Leishmaniasis Reference Center of the René Rachou Research Center;

*** Laboratory of Leishmaniasis Reference Center of the René Rachou Research Center.

mercialize the DAT, or the Royal Tropical Institute in Netherlands and the Prince Leopold Institute in Belgium, at a cost of US\$ 0.86 per reaction. The cost of the DAT-LPC reaction was estimated at US\$ 1.42 in a technical and economic feasibility study conducted by the Incentive Innovation Program of Fiocruz (Oliveira E, personal comunication). However, this estimate should still be interpreted with caution. In the present study, four lots of the IT LEISH were purchased and made available to health service units in Ribeirão das Neves. The difficulties encountered in purchasing the tests in certain instances were related to the unavailability of the requested tests from the manufacturer, delays in delivery and the short expiration date (six months) for certain lots. The manufacturer justified this unavailability due to worker strikes and poor weather in Europe. The expiration date was extended from six months to one year for the last acquired lot. Few rapid tests are available for VL diagnosis, and similar diagnostic limitations exist for malaria diagnosis, with only two rapid tests approved for use by the US Food and Drug Administration (FDA), in contrast with the 20 tests available for tuberculosis and the more than 30 tests for HIV diagnosis 18 .

For management of all activities in Ribeirão das Neves, one resident researcher in the city was based at the MHS throughout the study period. In a study evaluating implementation of a rapid HIV test, Bowles et al. ${ }^{19}$ suggested that participation of local professionals in the training of health professionals can encourage acceptance and implementation of diagnostic tests. The Brazilian Ministry of Health 17 notes that managerial support and articulation among all of the stakeholders involved in the process are crucial to the successful implementation of diagnostic tests in cities.

The average training time varied depending on the number of professionals trained in each course. In total, 162 city health professionals were qualified to perform the rapid test; however, only 151 IT LEISH kits were used during the training. This discrepancy can be explained by the fact that certain health professionals, despite being encouraged to perform the IT LEISH test, reported this step to be unnecessary because they were already performing other rapid tests in the city. Palamountain et al. 18 highlighted that even after implementation of a new diagnostic test occurs, continuous monitoring is essential because even the simplest tests can be incorrectly performed and interpreted by trained health professionals.

Replacing the diagnostic tests that are currently recommended by the Ministry of Health is important but entails two central problems. The first problem concerns the fragile and precarious nature of available human resources and infrastructure in many of Brazil's health service settings, and the second concerns the social, economic and regional inequalities that characterize Brazil, which directly reflect on the health system and limit the development of a fully efficient care system. What has been observed, particularly in remote regions, is the need to send collected 
Detailed costs of the items included in direct cost estimates of the diagnostic tests.

\begin{tabular}{|c|c|}
\hline Diagnostic test/Items included in the cost estimates & Values (US\$) \\
\hline \multicolumn{2}{|l|}{ IT LEISH } \\
\hline Remuneration for the laboratory technician & 0.85 \\
\hline Safety material * & 0.70 \\
\hline One kit & 5.07 \\
\hline Total & 6.62 \\
\hline \multicolumn{2}{|l|}{ DAT-LPC } \\
\hline Remuneration for the laboratory technician & 1.42 \\
\hline Safety material * & 1.39 \\
\hline Collection of biological material (blood) $* \star$ & 1.17 \\
\hline Consumable material $\star \star \star ~$ & 0.60 \\
\hline Equipment maintenance and calibration \# & 0.44 \\
\hline One kit & 0.42 \\
\hline Total & 5.44 \\
\hline \multicolumn{2}{|l|}{ Kala-Azar Detect } \\
\hline Remuneration for the laboratory technician & 1.71 \\
\hline Safety material * & 1.39 \\
\hline Collection of biological material (blood) $* \star$ & 1.17 \\
\hline Consumable material $\star \star \star ~$ & 0.07 \\
\hline Equipment maintenance and calibration \# & 0.39 \\
\hline One kit & 1.99 \\
\hline Total & 6.72 \\
\hline \multicolumn{2}{|l|}{ IFAT } \\
\hline Remuneration for the laboratory technician & 3.85 \\
\hline Safety material * & 1.39 \\
\hline Collection of biological material (blood) $* \star$ & 1.17 \\
\hline Consumable material $\star \star \star ~$ & 1.96 \\
\hline Equipment maintenance and calibration \# & 3.60 \\
\hline One kit & 0.57 \\
\hline Total & 12.54 \\
\hline \multicolumn{2}{|l|}{ Bone marrow aspirate } \\
\hline Remuneration for the doctor, the nurse and the laboratory technician & 18.35 \\
\hline Safety material * & 2.09 \\
\hline Collection of biological material (bone marrow) $\star \star$ & 6.21 \\
\hline Consumable material ${ }^{* \star \star}$ & 0.06 \\
\hline Equipment maintenance and calibration \# & 0.14 \\
\hline Total & 26.85 \\
\hline \multicolumn{2}{|l|}{ PCR } \\
\hline Remuneration for the laboratory technician & 7.31 \\
\hline Safety material * & 4.18 \\
\hline Collection of biological material (blood) $* *$ & 1.17 \\
\hline 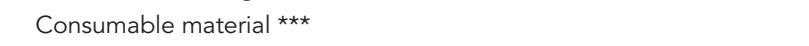 & 19.20 \\
\hline Equipment maintenance and calibration & 2.16 \\
\hline Total & 34.02 \\
\hline
\end{tabular}

DAT-LPC: direct agglutination test; IFAT: indirect fluorescence antibody test; PCR: polymerase chain reaction.

* Safety material: gloves and protective mask;

** Collecting biological material: cotton, needle, plastic tube, the surgical field, gauze, blades, anesthetic and antiseptic;

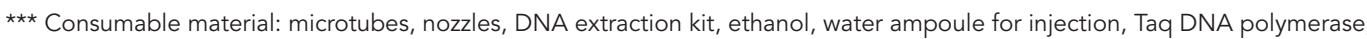
buffer solution, magnesium, primers, desoxibonucleotídeos fosfatados (DNTPs), ammonium persulphate, tetrametilinediamina (TEMED), molecular size pattern, formaldehyde, acetic acid and silver nitrate;

\# Equipment maintenance and calibration: thermocycler, pipettes, centrifuges, incubator, refrigerator and microscope. 
biological material to laboratories that are properly equipped to perform the IFAT and Kala-Azar Detect. Because the DAT-LPC only requires a centrifuge and a pipette, it can be implemented in decentralized laboratories. The IT LEISH rapid test could be performed at point-of-care, with the results available within 30 minutes. The incorporation of these two tests into decentralized services would alleviate the workload at central laboratories, which have a high demand for tests that require greater technical sophistication.

The need to move a patient suspected of having VL to receive health care also occurs in Ribeirão das Neves. With the exception of patients seen at basic referral units and the Clinic for Infectious and Parasitic Diseases, where biological material is collected and sent to the Municipal Laboratory and FUNED, all other units send patients to the Municipal Laboratory for blood collection. The average time from blood collection until result availability is four days (Guimarães $\mathrm{PN}$, personal comunications).

Economic evaluation of diagnostic technologies is necessary for VL control because the available alternatives and the respective resources involved differ significantly. Previous studies have evaluated the cost-effectiveness of VL drugs 20,21,22; however, studies focusing on diagnosis of the disease are scarce. In Brazil, where the public health system provides universal and integral care, the economic debate is of significant importance, given the need to apply and conserve resources appropriately.

From an economic point of view and considering only the direct costs, replacing the IFAT (US\$ 12.54) with the DAT-LPC (US\$ 5.44) and replacing the Kala-Azar Detect (US\$ 6.72) with the IT LEISH (US\$ 6.62) is recommended. Peeling et al. 23 emphasized that when a diagnostic test with acceptable performance is available, an evaluation panel's selection criteria for the test should include ease of use, storage conditions, shelf life, price and the need for other equipment in performing the test.

In this study, the costs of training each health care professional to perform the diagnostic tests were US\$ 7.13 for the IT LEISH and US\$ 9.93 for the DAT-LPC. These data are in contrast to those presented by Kyabayinze et al. 24, who estimated the cost of training a health care professional to perform a rapid test for malaria (P.f ICT, manufactured by ICT Diagnostics, South Africa) to be US\$ 101 in Uganda. The observed differences may be related to differences in the study settings and to the items included in the estimates performed by Kyabayinze et al. 24, such as training venue rent costs, transport, accommodation, food, time and salaries.

The IT LEISH exhibited the quickest performance time (30 minutes), followed by the DATLPC (50 minutes) and the Kala-Azar Detect (60 minutes). Bone marrow aspirate, the IFAT and the PCR test are more laborious, requiring 130 , 140 and 200 minutes, respectively, to be completed. These estimates were calculated based on the time spent by professionals on performing the diagnostic tests in health service units and did not include the costs related to sending the biological samples from the collection site to the laboratories that perform the test. Therefore, with the exception of the IT LEISH, the costs associated with all other tests may be underestimated. The cost of storage was not included in the estimate because the 61 health units in Ribeirão das Neves have different equipment for storage and because the time of storage varied significantly among the services. Additionally, it was not possible to estimate the cost of transport for each test individually because in the municipality, biological samples that need to undergo diagnostic tests for other diseases are sent along with samples intended for testing for leishmaniasis.

In this study, the overall cost of the training courses was estimated at US\$ $1,284.84$. This estimate is valid for the studied scenario and participating individuals; the cost of implementing the IT LEISH and the DAT-LPC in other cities and settings may vary considerably. It was not within the scope of this study to evaluate the cost of implementation of new diagnostic tests in health service settings that would need to install the minimum infrastructure required to perform the tests.

Other studies are in progress in Ribeirão das Neves to evaluate the performance of the IT LEISH and the DAT-LPC in routine situations, their acceptance by patients and health professionals and their cost-effectiveness in relation to current methods. This is the first time that the implementation process and the direct costs of VL diagnostic tests have been described in Brazil. The results indicate a satisfactory implementation process and may assist the Ministry of Health and the Brazilian states and cities in their decision-making regarding the best tests to be use from both an operational and an economic standpoint. 


\section{Resumen}

Este trabajo relata la puesta en funcionamiento y los costos de pruebas de diagnóstico de VL en un municipio endémico en Brasil: el test rápido (IT LEISH) y la prueba de aglutinación directa (DAT-LPC). Esta puesta en marcha comenzó por capacitar al personal sanitario del municipio para la realización de las pruebas. Para estimar los costos de la capacitación, se consideró la remuneración proporcional de todo el personal involucrado y los costos directos derivados de la aplicación de las pruebas. El estudio fue realizado entre noviembre de 2011 y noviembre de 2013. En ese periodo se realizaron 17 capacitaciones y se formaron 175 profesionales. Se calcula que el costo derivado de capacitar cada profesional para realizar el IT LEISH fue de 7.13 US\$ y 9.93 US\$ para el DAT-LPC. Los costos directos del IT LEISH y del DAT-LPC se estimaron en 6,62 US\$ y 5,44 US\$ respectivamente. La primera evaluación de la puesta en funcionamiento de las dos pruebas en este municipio señala que es viable descentralizar su realización, lo que amplía el acceso al diagnóstico de la VL en Brasil.

Leishmaniasis; Diagnóstico; Costos y Análisis de Costo

\section{Contributors}

T. S. Machado de Assis, P. N. Guimarães, E. Oliveira, V. Peruhype-Magalhães, L. I. Gomes and A. Rabello participated in conception and design, acquisition of data and analysis and interpretation of data; drafting the article and final approval of the version for publication.

\section{Acknowledgments}

This work was supported by CNPq, FAPEMIG and CPqRR/Fiocruz.

\section{References}

1. Sharma DA, Bern C, Varghese B, Chowdhury R, Haque R, Ali M, et al. The economic impact of visceral leishmaniasis on households in Bangladesh. Trop Med Int Health 2006; 2:757-64.

2. Sarnoff R, Desai J, Desjeux P, Mittal A, Topno R, Siddiqui NA, et al. The economic impact of visceral leishmaniasis on rural households in one endemic district of Bihar, India. Trop Med Int Health 2010; 15:42-9.

3. Uranw S, Meheus F, Baltussen R, Rijal S, Boelaert $\mathrm{M}$. The household costs of visceral leishmaniasis care in south-eastern Nepal. PLoS Negl Trop Dis 2013; 7:e2062.
4. Alvar J, Vélez ID, Bern C, Herrero M, Desjeux P, Cano J, et al. Leishmaniasis worldwide and global estimates of its incidence. PLoS One 2012; 7:e35761.

5. Luz ZP, Pimenta DN, Cabral ALLV, Fiúza VOP, Rabello A. A urbanização das leishmanioses e a baixa resolutividade diagnóstica em municípios da Região Metropolitana de Belo Horizonte. Rev Soc Bras Med Trop 2001; 34:249-54.

6. Costa CHN. Characterization and speculations on the urbanization of visceral leishmaniasis in Brazil. Characterization and speculations on the urbanization of visceral leishmaniasis in Brazil. Cad Saúde Pública 2008; 12:2959-63. 
7. Departamento de Vigilância Epidemiológica, Secretaria de Vigilância em Saúde, Ministério da Saúde. Leishmaniose visceral. Recomendações clínicas para redução da letalidade. Brasília: Ministério da Saúde; 2011. (Série A. Normas e Manuais Técnicos).

8. Siddig M, Ghalib H, Shillington DC, Petersen EA. Visceral leishmaniasis in the Sudan: comparative parasitological methods of diagnosis. Trans R Soc Trop Med Hyg 1988; 82:66-8.

9. Zijlstra EE, Siddig Ali M, El-Hassan AM, el-Toum IA, Satti M, Ghalib HW, et al. Kalazar: a comparative study of parasitological and methods and the direct agglutination test in diagnosis. Trans R Soc Trop Med Hyg 1992; 86:505-7.

10. Machado de Assis TS, Rabello A, Werneck G. Latent Class Analysis of diagnostic tests for visceral leishmaniasis in Brazil. Trop Med Int Health 2012; 17:1202-7.

11. Pedras MJ, Viana LG, Oliveira EJ, Rabello A. Comparative evaluation of direct agglutination test, rK39 and soluble antigen ELISA and IFAT for the diagnosis of visceral leishmaniasis. Trans R Soc Trop Med Hyg 2008; 102:172-8.

12. Carvalho SFG, Lemos EM, Corey R, Dietze R. Performance of recombinant K39 antigen in the diagnosis of brazilian visceral leishmaniasis. Am J Trop Med Hyg 2003; 68:321-4.

13. World Health Organization. Visceral leishmaniasis rapid diagnostic test performance. Geneva: World Health Organization; 2011. (Diagnostics Evaluation Series, 4).

14. Perhuype-Magalhães V, Machado-de-Assis TS, Rabello A. Performance of the Kala-Azar detect ${ }^{\circledR}$ and IT LEISH ${ }^{\circledR}$ rapid tests for the diagnosis of visceral leishmaniasis in Brazil. Mem Inst Oswaldo Cruz 2012; 107:951-2.

15. Oliveira E, Saliba SW, Saliba JW, Rabello A. Validation of a direct agglutination test prototype kit for the diagnosis of visceral leishmaniasis. Trans R Soc Trop Med Hyg 2013; 107:243-7.

16. Ministério da Saúde. Avaliação de tecnologias em saúde. Ferramentas para a gestão do SUS. Brasília: Ministério da Saúde; 2009. (Série A, Normas e Manuais Técnicos).
17. Ministério da Saúde. Orientação para a implantação dos testes rápidos para HIV e sífilis na atenção básica. Brasília: Ministério da Saúde; 2012.

18. Palamountain KM, Baker J, Cowan EP, Essajee S, Mazzola LT, Metzler M, et al. Perspectives on introduction and implementation of new point-of-care diagnostics tests. J Infect Dis 2012; 205:181-90.

19. Bowles KE, Clark HA, Tai E, Sullivan PS, Song B, Tsang J, et al. Implementing rapid HIV testing in outreach and community settings: results from an advancing HIV prevention demonstration project conducted in seven U.S. cities. Public Health Rep 2008; 123:78-85.

20. Boelaert M, Le Ray D, van der Stuyft P. How better drugs could change kala-azar control. Lessons from a cost-effectiveness analysis. Trop Med Int Health 2002; 7:955-9.

21. Olliaro P, Darley S, Laxminarayan R, Sundar S. Cost-effectiveness projections of single and combination therapies for visceral leishmaniasis in $\mathrm{Bi}$ har, India. Trop Med Int Health 2009; 14:918-25.

22. Meheus F, Balasegaram M, Olliaro P, Sundar S, Rijal S, Abul Faiz M, et al. Cost-effectiveness analysis of combination therapies for visceral leishmaniasis in the Indian subcontinent. PLoS Negl Trop Dis 2010; 4:e818.

23. Peeling RW, Mabey D, Ballard RC. Introducing new diagnostic into STI control programmes: the importance of programme science. Sex Transm Infect 2013; 89:115-9.

24. Kyabayinze DJ, Asiimwe C, Nakanjako D, Nabakooza J, Bajabaite M, Strachan C, et al. Programme level implementation of malaria rapid diagnostic test (RDTs) use: outcomes and cost of training health workers at lower level health care facilities in Uganda. BMC Central Public Health 2012; 12:1-8.

Submitted on $22 /$ Oct $/ 2014$

Final version resubmitted on 27/Mar/2015

Approved on 04/May/2015 